\title{
LER SEM SABER LER CONVENCIONALMENTE: PROPOSIÇÃO DE LEITURA PELO ALUNO E A IMPORTÂNCIA DA LEITURA EM VOZ ALTA
}

Lara Pardo Passadori (Pedagogia - FACCAT)

Prof. Dt. Luciana Ferreira Leal (Orientadora)

\section{RESUMO}

A proposta de trabalho foi realizada com crianças que ainda não tinham autonomia na leitura e na escrita a fim de comprovar a importância das proposições de leitura na aprendizagem dos alunos, uma vez que é lendo que se aprende a ler. Esse estudo propõe analisar que antes de ler convencionalmente, a criança constrói suas próprias estratégias de leitura, além disso, possui saberes riquíssimos que devem ser explorados a fim de que possam avançar até se apropriar do sistema de leitura e escrita e chegue, finalmente, à leitura convencional. Para isso, o professor, que possui um papel de extrema importância no processo de ensino-aprendizagem, deve garantir em sua rotina boas atividades de leitura e escrita, fazer intervenções pontuais que desafiem os alunos e propor bons agrupamentos para que haja reflexão e troca de saberes entre as crianças. Desse modo, é importante dizer que o contato com diferentes tipos de leitura é crucial, como, por exemplo, a leitura em voz alta, que é uma atividade valiosa na formação leitora e também as proposições de leitura pelo aluno, que o coloca na posição de leitor.

A proposta de trabalho foi realizada com crianças que ainda não tinham autonomia na leitura e na escrita a fim de comprovar a importância das proposições de leitura na aprendizagem dos alunos, uma vez que é lendo que se aprende a ler. Vale ressaltar que, antes de ler convencionalmente, a criança constrói suas próprias estratégias de leitura, além disso, possui saberes riquíssimos que devem ser explorados a fim de que possam avançar até se apropriar do sistema de leitura e escrita e chegue, finalmente, à leitura convencional. Para isso, o professor, que possui um papel de extrema importância no processo de ensino-aprendizagem, deve garantir em sua rotina boas atividades de leitura e escrita, fazer intervenções pontuais que desafiem os alunos e propor bons agrupamentos para que haja reflexão e troca de saberes entre as crianças. Desse modo, é importante dizer que o contato com diferentes tipos de leitura é crucial, como, por exemplo, a leitura em voz alta, na qual é uma atividade valiosa na formação leitora, também as proposições de leitura pelo aluno, que o coloca na posição de leitor, assim como tantas outras atividades, que são relevantes e necessárias para a formação do aluno.

A presente pesquisa foi realizada na Estância Turística de Tupã, localizada no estado de São Paulo, na EMEIEF Jardim Nossa Senhora de Fátima, no período da manhã, numa sala de alfabetização, especificamente no $1^{\circ}$ ano $\mathrm{B}$, na qual há 15 alunos alfabéticos, 2 silábicos alfabéticos, 2 silábicos com valor sonoro convencional, 0 silábico com valor sonoro não convencional e 1 pré-silábico, sendo que um dos alunos tem laudo de deficiência intelectual moderada. Ao longo do ano letivo de 2015, foram desenvolvidas nesta sala de aula proposições de leitura, especificamente com os alunos não alfabéticos, a fim de investigar se é possível ler sem saber ler convencionalmente. 


\section{SEMINÁRIO DE PESQUISA EM CIÊNCIAS HUMANAS - SEPECH \\ Humanidades, Estado e desafios didático-científicos \\ Londrina, 27 a 29 de julho de 2016}

É importante ressaltar que, nesse período, participei de formações específicas realizadas na instituição de ensino superior Faculdades Faccat de Tupã sobre proposições de leitura para alunos que ainda não leem convencionalmente. Essas formações foram ministradas pela Professora Doutora e orientadora Luciana Ferreira Leal. Essas formações contribuíram significadamente com esta pesquisa, uma vez que estes estudos sobre a leitura embasaram a pesquisa bibliográfica e norteou a pesquisa de campo a fim de obter uma melhor compreensão do tema a ser pesquisado.

O trabalho foi dividido em etapas: primeiro foi realizada uma entrevista com a professora regente da sala, contendo algumas questões sobre proposições de atividades de leitura feita pelo aluno. Depois, observei as proposições de atividades de leitura em sala de aula para quem não sabe ler convencionalmente e fiz diversos relatórios sobre as condições didáticas garantidas e as fases dessas atividades, como o antes, o durante e o depois. Em seguida, um planejamento da aula foi elaborado com a participação da professora regente e a coordenadora pedagógica da escola, para assim serem executadas as gravações das atividades para transcrição e análise para a construção do relatório final.

É importante destacar que a criança pode, por meio dos sinais gráficos, reproduzir verbalmente os sons representados pela letra impressa, pois "[...] para aprender a ler e a escrever é preciso pensar sobre a escrita, pensar sobre o que a escrita representa e como ela representa graficamente a linguagem”. (BRASIL, 1997, p. 82). Para adquirir conhecimentos é necessário que as crianças interpretem o que ouvem, pensem e reflitam a partir do que já conhecem, por isso, desde muito pequenas, elas podem e devem conhecer os diferentes materiais de leitura, saber para que serve e tentar descobrir o que está escrito. Dentro desta etapa, é importante o processo de construção da leitura, no qual a criança aprende que existe um conjunto de técnicas para adquirir habilidades na codificação da escrita. "A criança ouve texto lido ou as histórias contadas, compreende-os e os interpreta dentro das suas limitações". (BRASIL, 2010, p. 37).

Quando o aluno não consegue decodificar completamente o texto impresso e precisa descobrir o que está escrito, sua tendência é buscar adivinhar o que não consegue decifrar, recorrendo ao contexto no qual os escritos estão inseridos, bem como às letras iniciais. "Na leitura de textos, a criança em fase de alfabetização, não só se aproxima do livro como fonte do conhecimento e prazer, mas também exerce um papel importante na formação da expressão verbal”. (CADEMARTORI, 1994, p. 72).

A partir dessa reflexão, podemos dizer que no momento em que a criança começa a entender o que está escrito, ela compreende o que é um meio de comunicação, onde ela consegue se comunicar com outras pessoas. Um dos processos de construção dos saberes acontece quando as crianças têm a oportunidade de confrontar seus conhecimentos com os colegas, e para isto é indispensável o trabalho em duplas ou grupos. A leitura em dupla ou em grupos é uma atividade que acrescenta aos alunos conhecimento, pois com a mediação da professora faz com que confrontem a leitura e percebam que, como esta leitura está, em relação à do parceiro da dupla, permitindo que façam a reflexão e que tirem dúvidas.

Assim, entendemos que essa atividade é uma proposta que tem que ser realizada com mais frequência dentro da sala de aula, pois possibilita aos alunos o enriquecimento do seu conhecimento por meio da exercitação dessa prática chegando à uma experiência enriquecedora. Desse modo esta pesquisa de leitura deve ser trabalhada 


\section{SEMINÁRIO DE PESQUISA EM CIÊNCIAS HUMANAS - SEPECH \\ Humanidades, Estado e desafios didático-científicos \\ Londrina, 27 a 29 de julho de 2016}

com todas as hipóteses possíveis, mesmo sem a criança saber ler convencionalmente, ela deve ter a chance de ler para que se desenvolva a sua oralidade naturalmente. E que atribua significados e possa adquirir conhecimentos que enriqueça se vocabulário.

Diante dessas considerações, realizei a seguinte entrevista com a professora regente do $1^{\circ}$ ano:

1- Em sua opinião, o que é uma atividade de proposição de leitura para alunos que ainda não sabem ler convencionalmente?

É uma proposta de trabalho em que o professor proporciona ao aluno que ainda não está alfabetizado a oportunidade de refletir sobre o sistema alfabético de escrita e leitura e antecipar o que pode estar escrito.

2- Você considera essa prática importante? Por quê?

Sim, pois através dessas propostas (roda de gibi, leitura de legenda, lista dos nomes dos alunos, textos de memória...) os alunos vão construindo estratégias para se apropriarem cada vez mais da leitura.

3- O que os alunos aprendem com essa atividade?

O contato com esse tipo de proposta faz com que o aluno reflita sobre o funcionamento do sistema de escrita e quando essa reflexão é constante, há um maior desenvolvimento das estratégias de leitura, ele busca cada vez mais recursos para "ler". Ele compara palavras, seleciona, olha para todas as pistas e só depois verifica o que está escrito. Enfim, aprende a ser leitor atuante.

4- A proposição de leitura de textos pelos alunos pode ser realizada em uma classe de alfabetização? Por quê?

Sim, essa atividade deve ser realizada em uma sala de alfabetização, momento em que o aluno estabelece a relação entre o falado e o escrito, oferecer textos logo no início do ano faz com que conheçam suas funções. E é nessa fase que o aluno faz antecipações a partir dos conhecimentos que possui: letra inicial do seu nome, dos nomes dos colegas ou algo que seja significativo para ele. Em uma sala já alfabetizada a proposta já deverá ser de fluência leitora.

5- A proposição de leitura por alunos não alfabéticos é uma atividade permanente em sua rotina? Qual o critério você utiliza para selecionar as proposições?

Sim, essa atividade é permanente em minha rotina, pois contempla uma das expectativas do $1^{\circ}$ ano. $\mathrm{O}$ critério é utilizar sempre atividades que desafiem os alunos, ampliando seus saberes e fazendo-os refletir e buscar estratégias mais adequadas para avançarem. Importante ressaltar que estão sempre dentro de um projeto ou sequência didática.

6- Se a resposta à pergunta anterior foi sim, a partir de que momento as propostas de atividades de leitura por alunos não alfabéticos passou a fazer parte de sua rotina escolar? E o que mudou?

$\mathrm{Na}$ verdade ela esteve presente desde o início do ano letivo, momento no qual verifiquei através das sondagens iniciais que havia um grande número de alunos que ainda não estavam alfabéticos. O resultado mostra que os alunos vêm avançando cada vez mais no processo de desenvolvimento das competências leitora e escritora.

Por meio das respostas obtidas pela docente, durante a entrevista, notei que ela detém conhecimentos significativos sobre o que os alunos aprendem e qual a importância das proposições de leitura pelo aluno. Vale ressaltar que a professora tem ciência de que as atividades de leitura realizadas com crianças que não leem 


\section{SEMINÁRIO DE PESQUISA EM CIÊNCIAS HUMANAS - SEPECH \\ Humanidades, Estado e desafios didático-científicos \\ Londrina, 27 a 29 de julho de 2016}

convencionalmente são de suma importância para o processo de alfabetização, uma vez que a educadora relata que a proposição de leitura pelo aluno é uma atividade permanente em sua rotina, e os critérios de escolha dessas proposições são os desafios oferecidos aos alunos, os quais devem ampliar seus saberes e fazê-los refletir e buscar estratégias para avançarem. Pode-se dizer que a professora nota os avanços por parte dos alunos e colhe bons resultados, pois sabe como trabalhar e a importância de se trabalhar com proposições de leitura nos anos iniciais.

Após a entrevista com a professora, construímos o seguinte planejamento de aula: Leitura pelo aluno de títulos de contos, a qual tinha os objetivos de ler sem saber ler convencionalmente; descobrir onde está escrito aquilo que se sabe estar escrito. Para isso, os alunos que ainda não leem convencionalmente foram organizados em duplas ou trios, de acordo com seus saberes. Antes da aula, organizamos as duplas/trio de crianças, procurando formar duplas/trios produtivos de trabalho, o que significa que os níveis de conhecimento de ambos os integrantes não sejam idênticos, e sim próximos. Num primeiro momento, relembramos com os alunos os pontos principais do livro, como: nome do livro, autor, ilustrador, do que se trata, dos personagens e por fim, dos títulos das histórias contidas no livro no qual, anteriormente, foi lido na proposta de leitura em voz alta. Após relembrarem os itens mencionados, foi necessário que o professor explicasse a atividade: Que o(a) professor(a) retirou os títulos dos contos contidos no livro e os classificou em forma de lista a fim de que os alunos localizem os títulos que a professora solicitar. Por fim, a professora teve que garantir a leitura aleatória dos títulos, e não em ordem; além disso, favoreceu a troca de informações entre os alunos, socializando as diferentes estratégias de leitura utilizadas pelas duplas/trio, propiciou a utilização dos indícios quantitativos e qualitativos promovidos pelos títulos e, sobretudo, realizou reflexões entre "o que está escrito" e "o que se pode ler" e solicitar que os alunos justifiquem suas escolhas.

Vale ressaltar que, antes dessa atividade a professora leu o livro na proposição de Leitura em voz alta, a qual é fundamental, pois amplia o repertório cultural do aluno, aumenta a familiaridade com a língua, desenvolve o comportamento leitor, além de colaborar no processo de alfabetização. Ela não só proporciona aos alunos o desenvolvimento da imaginação e das emoções, mas também amplia o vocabulário do leitor e dos ouvintes, pois desenvolve-se durante a leitura uma capacidade linguística.

Maria de Lourdes de Souza Kriegl, em seu artigo Leitura - Um desafio sempre atual (2002), diz que "o ato de ler é o processo de 'construir significado' a partir do texto. Isso se torna possível pela interação dos elementos textuais com os conhecimentos do leitor. Quanto maior for a concordância entre ler, maior a probabilidade de êxito na leitura" (p. 2). Assim, para a autora, "aprender a ler é um processo social de construção de significado que engloba interações entre ideias, pessoas e acontecimentos" (idem, p. 2). Desde cedo, as pessoas, nos processos de leitura e produção de textos, aprendem a agir em relação a seus educadores, familiares, comunidades, etc. Deste modo, "a leitura é um desafio que tem como objetivo um trabalho de linguagem" (idem, p. 2).

A escolha do livro a ser lido é de extrema importância, livros de má qualidade literária não podem contribuir em todas as dimensões com o aprendizado do aluno, por isso é necessário ler bons livros, de bons autores. A qualidade das aprendizagens sobre a linguagem que podem ser obtidas a partir do contato com a 


\section{SEMINÁRIO DE PESQUISA EM CIÊNCIAS HUMANAS - SEPECH \\ Humanidades, Estado e desafios didático-científicos \\ Londrina, 27 a 29 de julho de 2016}

leitura é outro aspecto que merece ser considerado no processo de escolha de textos literários. Desse modo, a leitura pode ser realizada em roda ou com os alunos em seus respectivos lugares, mas o principal é o silêncio e as estratégias de leitura que cativem a atenção dos ouvintes.

As antecipações são essenciais, quando a professora lê o título do livro e mostra a capa para os alunos, ela desperta neles a curiosidade do que vai acontecer na história, o que pode e o que não pode ocorrer, quais são os personagens, como são, se terá desfechos bons ou ruins, enfim, desenvolve a imaginação da criança e proporciona um momento de interação com a classe, além de apresentar a leitura como um processo cognitivo. Tornar a leitura como processo cognitivo implica considerar que, para ler, fazemos e testamos hipóteses sobre o conteúdo de um texto, ou seja, fazemos antecipações a respeito do conteúdo do mesmo. Neste caso, quando o leitor confirma suas predições, ele prossegue sua leitura. Quando não, ele modifica sua estratégia de leitura (Kato, 1985).

Durante a leitura, a professora deve ter uma boa postura, pois a história se torna interessante quando se causa suspense, ação, emoção ou qualquer outro sentimento através da entonação da voz. Portanto, as pausas e a entonação são fundamentais. Uma atitude desnecessária durante a leitura é pará-la para explicar ou dizer significados de palavras, pois os alunos irão compreendê-las através do contexto da história. As pausas seriam para questionar os alunos sobre o que irá acontecer, por exemplo.

Após a leitura os alunos sempre levantam as mãos ansiosos para falar sobre o que gostou, o que não entendeu, o que chamou mais a sua atenção, enfim, é o momento no qual eles mais participam. Por isso a professora deve conduzir um diálogo construtivo, elaborando interrogações desafiantes aos alunos e se possível voltar e reler partes do texto para melhor compreensão do mesmo.

Sendo assim, destacaremos alguns pontos marcantes sobre a transcrição da aula: A atividade de leitura em voz alta é uma atividade permanente na rotina desta professora pesquisada, desse modo, durante 10 dias a professora leu, garantindo todos os procedimentos necessários como: o antes, durante e depois, o livro Contos de morte morrida do autor Ernani Ssó. Os alunos gostaram muito do livro e por isso a professora aproveitou a oportunidade para propor uma atividade de leitura com os alunos que ainda não leem com autonomia envolvendo o livro, que os alunos tanto gostaram:

"Professora: Eu trouxe pra vocês hoje, pra gente conversar... Caio, eu trouxe vocês, pra gente conversar, propor uma atividade de um livro que a gente acabou de ler esta semana.

Professora: Como chama este livro?

Britney: Contos de morte morrida!

Professora: Isso, contos de morte morrida! E esse livro de contos... Vocês lembram quem é o autor, quem é o autor deste livro? Não? Ninguém lembra? Ele se chama Ernani?

\section{Britney: Ssó."}

Inicialmente a professora relembra com os alunos alguns dados importantes sobre o livro, como quem o escreveu, por exemplo. É muito importante que os alunos tenham conhecimento sobre o autor dos livros que se lê, para que se consolide o comportamento leitor e também para enriquecimento do conhecimento cultural dos alunos. 


\section{SEMINÁRIO DE PESQUISA EM CIÊNCIAS HUMANAS - SEPECH \\ Humanidades, Estado e desafios didático-científicos \\ Londrina, 27 a 29 de julho de 2016}

"Professora: Ssó! Isso mesmo! O Ernani Ssó escreveu vários contos sobre a morte. E esses contos aqui, eles são parecidos com os contos de fadas?

\section{Alunos: Não!}

Professora: Não, por quê? Que diferença eles tem dos contos de fadas? $O$ que tem nos contos de fadas, em, Britney?".

Neste momento, a professora compara os contos do livro de Ernani Ssó com os contos de fadas, o que é de extrema importância na formação de leitores, uma vez que eles precisam saber diferenciar os gêneros textuais.

"Britney: Princesas...

Mariana: Sapatinho de Cristal...

Professora: E como é o final dos contos de fadas?

Britney: Que eles se casam!

Mariana: "E viveram felizes para sempre!".

As alunas mostram as características dos contos de fadas relatando personagens e até mesmo utilizando expressões marcantes dos contos de fadas, o que nos mostra que as crianças possuem saberes preciosos.

"Professora: Isso, eles têm um final feliz! E estes contos aqui? Eles também são com final feliz?

Alunos: Não!

Professora: E como eles terminam sempre?

Alunos: Morrem!

Professora (assustada): Hãaaaam! E quem que leva?

Alunos: A morte!

livro?

Professora: A morte! Quem aparece em todas estas histórias que tem no

\section{Alunos: A morte!}

Professora: E o que ela traz nas mãos sempre?

Luiz Fabiano: A gadanha!

Professora: A gadanha!!! E será que, é, porque a morte aparece em todas as histórias, que o nome dos títulos das histórias também traz o nome da morte? Vamos lembrar os nomes? Olha só... A morte e o escritor, A morte e o caçador, A morte e o pescador, A morte e o médico, A morte e a velha, A morte e os gêmeos, A morte e o estalajadeiro, A morte e o paxá, A morte e o fujão, e A morte e o ferreiro."

A professora relembra com os alunos todas as histórias. Isso é muito importante para que a proposição feita pela professora tenha mais sentido para o aluno, pois uma atividade sem uma sequência didática, ou seja, uma atividade solta na rotina, não tem muito significado para a criança e não tem o mesmo êxito que uma proposição dentro de uma sequência.

Após esse momento, a professora deixa os alunos olharem o cartaz por um tempo sem interferir a fim de descobrir o que os alunos descobririam sem intervenção. Vale ressaltar que o professor não precisa fazer intervenções o tempo todo, pois, fazendo boas parcerias entre os alunos pode ser muito mais significante e produtivo, permitindo que os alunos avancem mais por meio dessa reflexão que essa interação proporciona. Por isso a professora faz bons agrupamentos com os alunos de saberes próximos.

"Professora: Qual é a palavra... Vocês estão achando alguma coisa parecida entre as histórias? “ 


\section{SEMINÁRIO DE PESQUISA EM CIÊNCIAS HUMANAS - SEPECH \\ Humanidades, Estado e desafios didático-científicos \\ Londrina, 27 a 29 de julho de 2016}

Esta pergunta da professora foi muito importante, uma vez que todos os títulos começavam da mesma maneira e os alunos teriam que se atentar para a palavra final do título.

"Luís Guilherme e Mariana (com tom de insegurança): Não!

Luiz Fabiano: Tudo parecido aqui oh! (Aponta para os títulos no cartaz indicando as letras) $A, A, A, M, M, M, O, O, O, R, R, R \ldots$

Luís Guilherme: Tudo tá igual!

OS ALUNOS PERCEBEM QUE OS TÍTULOS COMEÇAM COM AS MESMAS PALAVRAS.

Luiz Fabiano: T, T, T, E, E, E, A... (O aluno para o dedo no segundo título que não tinha mais a letra $A$ )

Professora: Aí muda né, Luiz? O que será que está repetido aí, qual será a palavra que repete em todas as histórias? Em, Mariana?".

A professora faz outro questionamento importante, ela não revela qual a palavra que se repete. Embora já tenha lido todos os contos e relembrado todos os títulos, ela apenas pergunta qual a palavra que está se repetindo em todos os títulos sem dizer que palavra é esta.

"Mariana: Hum...

Professora: Qual será a palavra que está repetida em todas as histórias?

Mariana: Morte!

Professora: Ah, vocês concordam com a Mariana?

Luis Guilherme: Morte!

Luiz Fabiano: Sim!

Professora: Sim? Ela diz que tá repetindo em todos os nomes "A morte”! E onde está escrito, Mariana, a morte?".

A professora pede para que a aluna localize a palavra que está repetindo, no caso, morte.

"Mariana (indicando a palavra morte com o dedo): Aqui!

Professora: Muito bem! Agora vou pedir pra vocês juntos acharem onde está escrito "A morte e o Escritor". A morte e o Escritor!".

Diante disso dos trechos expostos e dos estudos teóricos, considero que as proposições de leitura devem ocupar um horário nobre do planejamento de todos os professores, pois, sobretudo elas são, e sempre serão, atividades edificantes, prazerosas e essenciais para a formação leitora. Em função disso, pesquisar sobre proposições de leitura, me permitiu ampliar o conhecimento teórico e prático sobre o sistema de leitura e escrita, as concepções de alfabetização e as boas práticas de ensino, além de conhecer as diferentes estratégias de leitura utilizadas pelas crianças. Diante dessas contribuições, consideramos também que o professor possui um papel de extrema importância no processo de ensino-aprendizagem, como mediador, uma vez que suas intervenções são decisivas e podem contribuir com a construção do saber do aluno quando realizada adequadamente ou até mesmo prejudicar o avanço da criança quando a intervenção for inadequada.

A título de considerações finais, é importante ressaltar que esta pesquisa nos mostrou que é possível ler sem saber ler convencionalmente, uma vez que antes da criança ler convencionalmente, ela possui suas próprias estratégias de leitura, E saberes riquíssimos que devem ser explorados a fim de que avanços ocorram até a criança se apropriar do sistema de leitura e escrita e chegar, finalmente, à leitura convencional. 


\section{SEMINÁRIO DE PESQUISA EM CIÊNCIAS HUMANAS - SEPECH \\ Humanidades, Estado e desafios didático-científicos \\ Londrina, 27 a 29 de julho de 2016}

\section{REFERÊNCIAS}

. Sobre a leitura e a formação de leitores. São Paulo: SEE: Fundação Vanzolini, 2004.Texto parcialmente publicado no portal www.educarede.org.br.

BARROS, R. M. A. Ler quando não se sabe. Cadernos da Escola, Brasília, MEC/SEF, 1999.

BRASIL. Parâmetros Curriculares Nacionais - Língua Portuguesa. Brasília: MEC/SEF, 1997.

BRAKLING, Kátia Lomba. A leitura da palavra: aprofundando compreensões para aprimorar as ações. Concepções e prática educativa. São Paulo (SP): SEE de SP/CEFAI; 2012.

BREDA, T. Leitura feita pelo aluno, antes de saber ler convencionalmente. Publicado em Alfabetização, Março 2009. Disponível em: $<$ http://revistaescola.abril.com.br/lingua-portuguesa/alfabetizacao-inicial/comeco431529.shtml>. Acesso em: 02 de dez. de 2015.

CASTEDO, Mirta Luísa. Onde está escrito, o que está escrito, como está escrito?_Uma situação didática para poder ler antes de saber ler. Artigo do periódico: Lectura y Escritura - Enseñar y aprender a leer. Ediciones Novedades Educativas. Buenos Aires. 1999.

FERNANDES, Disponível em $\quad<$ http://alemdasletrasariquemeshotmailcom. blogspot.com.br/2011_01_28 archive.html > 06 jan.2014.

FERREIRO, Emilia e TEBEROSKY, Ana. Psicogênese da Língua Escrita. Porto Alegre: Artmed, 1999.

FERREIRO, Emilia. Alfabetização em processo. $11^{a}$ ed. São Paulo, Cortez, 1996.

. Reflexões sobre alfabetização. São Paulo, Cortez, 1985.

GUIA de estudo para o horário de trabalho coletivo. Por que o professor deve ler para o aluno? Bloco 7. Texto 19, p. 147 a 161.

KAUFMAN, Ana Maria \& RODRÍGUEZ, Maria Helena. Escola, leitura e produção de textos. Porto Alegre: Artmed.

LERNER, Delia. Ler e escrever na escola. O real, o possível e o necessário. Porto Alegre. Artmed. 2002.

LERNER, Délia, “É possível ler na escola?”- Ler e escrever na escola o real, o possível e o necessário. Porto Alegre: Armed, 2002.

LIMA, Bárbara Carvalho Marques Toledo; AZEVEDO, Heloísa Helena de Oliveira. Leitura fruição em sala de aula: subsídio para a formação do leitor. Cadernos da Pedagogia. São Carlos, Ano 5 v. 5 n. 9, p. 66-79, jan-jun. 2011. 


\section{SEMINÁRIO DE PESQUISA EM CIÊNCIAS HUMANAS - SEPECH \\ Humanidades, Estado e desafios didático-científicos \\ Londrina, 27 a 29 de julho de 2016}

PARÂMETROS CURRICULARES NACIONAIS - Língua Portuguesa. Brasília: MEC/SEF, 1997.

PEREIRA, VALQUÍRIA. A importância da leitura em sala de aula para a fluência leitora. Revista Nova Escola. Julho de 2013.

SSÓ, Ernani. Contos de morte morrida. São Paulo. Companhia das letrinhas. 2007.

TEBEROSKY, A; COLOME, T. Aprender a Ler e a Escrever: uma proposta construtivista. Porto Alegre: Artmed, 2003.

WEISZ, Telma. O Diálogo entre o ensino e a aprendizagem. São Paulo: Ática, 1999. 